\title{
Deep Roots? Behavioral Inhibition and Behavioral Activation System (BIS/BAS) Sensitivity and Entrepreneurship
}

For final version and referencing, please see Journal of Business Venturing Insights.

Lerner, D., Hatak, I., \& Rauch, A. (2018). Deep Roots? Behavioral Inhibition and Behavioral Activation System (BIS/BAS) Sensitivity and Entrepreneurship. Journal of Business Venturing-Insights.

Acknowledgements:

The authors acknowledge helpful comments from an anonymous reviewer, and from Dr. Diemo Urbig, on previous versions of this work. 


\title{
Deep Roots? Behavioral Inhibition and Behavioral Activation System (BIS/BAS) Sensitivity and Entrepreneurship
}

\begin{abstract}
A growing number of studies suggest a link between disinhibition and entrepreneurship. Separately, psychology literature has theorized and empirically shown that the roots of disinhibition can largely be traced to two psychophysiological systems - the behavioral inhibition system (BIS) and behavioral activation system (BAS). Despite BIS/BAS sensitivity underling constructs linked to venturing (e.g. impulsivity, clinical profiles, personality, motivation), and the existence of validated self-report scales for BIS/BAS operationalization, research has almost entirely yet to examine the connection between BIS/BAS sensitivity and entrepreneurship. We explore whether BIS and BAS sensitivities are related to entrepreneurial action and performance. Two studies are presented, and serve as a basis for further inquiry. Our examination of BIS/BAS (and associated Reinforcement Sensitivity Theory) in entrepreneurship adds to prior research that has largely looked to higher-order constructs. This work further opens and substantiates emerging research in entrepreneurship involving for example impulse-driven action, clinical constructs such as attention deficit/hyperactivity disorder, and underlying drivers of individual differences.
\end{abstract}

Keywords: entrepreneurship; behavioral inhibition; behavioral activation; reinforcement sensitivity theory; impulsivity; ADHD.

\section{Introduction}

A number of entrepreneurship studies have recently suggested the relevance of behavioral disinhibition (Lerner 2016), of acting on impulse/impulsivity (Wiklund et al. 2016; 2017), and of related constructs such as ADHD (Lerner, Verheul \& Thurik 2018; Thurik et al. 2016; Verheul et al. 2015; 2016). Building on these, Lerner, Hunt and Dimov (2018: 56) suggest disinhibition is an important yet illusive "alternative logic [of] entrepreneurial action." Implicated in, and underlying the aforementioned constructs, are two psychophysiological systems: the behavioral inhibition system (BIS) and the behavioral activation system (BAS) (Gray 1970; 1982; 1994; 
Nigg 2000). The two systems form the essence of Reinforcement Sensitivity Theory ${ }^{1}$ (Carver \& White 1994; Corr 2004; Gray 1991), which suggests the following: 1) BIS is the aversive motivational system, largely inhibiting behavior in response to potential threat; 2) BAS is the appetitive motivational system, activating behavior in response to potential reward; 3) the more sensitive a system, the more likely it is to be triggered/activated and the stronger the response.

To briefly elaborate on each system: BIS is sensitive to stimuli associated with punishment and threat posed by novelty; it is related to anxiety, risk assessment, uncertainty avoidance and inhibition of movement (e.g., Gray \& McNaughton 2000). BAS, on the other hand, is sensitive to potential reward; it is related to excitement, goal drive, novelty seeking (Cloninger 1987), and hyperactive-impulsive ADHD behaviors (Nigg 2000). BAS can be parsed into three subdimensions: Reward Responsiveness $(B A S-R R)$ focuses on the strength of the reaction to the occurrence or anticipation of a reward; Drive $(B A S-D)$ involves the primacy of moving to get what is desired; Fun Seeking (BAS-FS) captures the "desire for new rewards and a willingness to approach a potentially rewarding event on the spur of the moment" (Carver \& White 1994: 322). Individual differences in BIS sensitivity and BAS sensitivity are understood to be stable (e.g., Carver \& White 1994; Gray 1994).

The relevance and potential connection of BIS/BAS sensitivity to entrepreneurship looms large. Entrepreneurship is characterized by uncertainty and novelty (McMullen \& Dimov 2013), with myriad environmental cues of potential threat and reward. Thus, interpersonal differences in BIS and BAS sensitivities may affect not only entrepreneurial intent (Geenen et al. 2016), but

\footnotetext{
${ }^{1}$ The existence of the theorized systems has been verified extensively in humans as well as in animals (e.g., Carver \& White, 1994; Gray 1970; 1982; 1991). Note: A third system characterized by fight-or-flight has also been conceptualized. In this paper, we limit our focus to the core original BIS/BAS systems, considering the data available and that behavioral inhibition and behavioral activation sensitivities reason to be more central to entrepreneurship. As such, inquiry into fight-or-flight as well as later sub-delineations of the original BIS, are among many future research opportunities.
} 
may also underlie and shape entrepreneurial action and outcomes. Related to this and a growing conversation in entrepreneurship, Lerner and colleagues (2018a) present three cases of entrepreneurs appearing to act in line with high-BAS/low-BIS, and suggest its relevance in lessreasoned pathways to entrepreneurship.

However, beyond early and overly abbreviated explorations (Lerner 2010; Lerner \& Fitza 2012), there appears to be only one published article empirically examining BIS/BAS in entrepreneurship - Geenen and colleague's (2016) study of entrepreneurial intent. Accordingly, further examination of BIS/BAS in entrepreneurship is important for grounding and shaping emerging conversations. Overall, BIS/BAS Reinforcement Sensitivity Theory (RST) offers a general, parsimonious framework for understanding and integrating a diversity of recent research. For example, with reinforcement sensitivity being able to explain the origin and magnitude of an impulse, and at the root of stable differences in impulsivity (Gray, 1994; Simillie et al., 2006) and personality (e.g. Corr 2015; Corr, DeYoung, \& McNaughton 2013), RST is capable of integrating disparate entrepreneurship research on say, sensation seeking and ADHD. More fine-grained reasons why a look through the BIS/BAS RST lens is important and has the potential to further stimulate research and theory development in entrepreneurship include the following.

First, motivational theories explaining and predicting the direction, amplitude, and persistence of individuals' behavior (Kanfer 1992) -- such as attempting to start a business venture as well as running one -- are important to understanding entrepreneurship (e.g., Locke \& Baum 2007). Prior research, largely focusing on higher-order human psychology, has advanced the understanding of top-down reasoned goal selection, pursuit, and associated entrepreneurial behavior. Such research has indeed made important contributions, based on the premise of 
higher-order reasoning preceding and underlying action (e.g., deliberate assessments of one's aptitudes and their mesh with the skills needed of venturing, of feasibility, and/or of goals) (Lerner, Hunt \& Dimov 2018). We fully agree that reasoned, consciously held goals often motivate and direct complex human behavior. Concurrently, motivation and behavior can also originate from uninhibited bottom-up appetitive impulses (Carver \& White 1994; Carver 2005). In contrast to top-down, bottom-up pathways refer to that which not directed by intentional thought and associated top-down (prefrontal neocortex) circuitry - but rather involves more basic and reactive psychophysiology and upward neurocircuitry and responding (Carver 2005; Phelps 2006; Phelps et al 2001). The possibility of motivation and behavior being fueled to some degree by uninhibited bottom-up appetitive impulses may be particularly relevant in an entrepreneurial context where individuals have to act quickly and under uncertainty (Lerner, Hunt \& Dimov 2018; Wiklund et al. 2017). Consequently, it is worthwhile to look into BIS/BAS sensitivities as they specifically address the deeper, bottom-up hedonic part of motivational theory.

Second, entrepreneurship is understood as a process involving motives, actions, and venturing outcomes (McMullen \& Dimov 2013). BIS/BAS sensitivity might differentially affect different aspects of entrepreneurship. For example, the role of BIS/BAS might vary depending on specific components or aspects of the entrepreneurial process because of the diverse nature of entrepreneurial venturing itself (e.g., Baron 2008; Shane 2003). The perception of and reaction to stimuli associated with developing entrepreneurial intentions, versus actually attempting to start a venture, versus ultimately generating sustained entrepreneurial profit are apt to differentially involve behavioral inhibition and behavioral activation systems (cf. Lerner et al., 2018b). For example, in terms of entrepreneurial intentions in individuals with no prior venturing experience, Geenen and colleagues (2016) found that reward responsiveness (BAS-RR) was negatively 
related to entrepreneurial intentions, while fun seeking (BAS-FS) was positively associated with entrepreneurial intentions. This makes sense given, respectively, the immediacy of rewards in wage-employment and the thrilling idea of venturing (e.g., Baron 2007). Yet to take action under uncertainty - on multiple fronts ranging from creative prototyping, to raising finance, to dealing with regulations, to recruiting employees and so forth (Hatak \& Snellman, 2017; Lerner et al., 2018b) - different sensitives may be more relevant, such as high BAS-Drive. Finally, given competitive pressures and that entrepreneurial rents do not last indefinitely, what serves longterm venture performance: a desire for new rewards (BAS-FS) while also keeping at the currently rewarding opportunity (BAS-RR), high drive (BAS-D), and/or a sufficiently limited sensitivity to threat to be willing to take the risk of innovation (low BIS)? Suffice to say, the role of BIS/BAS sensitivity in venturing is unknown and may change according to the particular entrepreneurial context (e.g. stage of the entrepreneurial process) (cf. Baron \& Markman 2005; McMullen \& Dimov 2013).

Third, BIS/BAS sensitivity has been related to deviant workplace behavior (Diefendorff \& Mehta 2007; Hogan \& Holland 2003). Additionally, research in clinical psychology indicates that BIS/BAS can be used to analyze sub-clinical as well as clinical behavior (Bijttebier et al. 2009). Accordingly, BIS/BAS Reinforcement Sensitivity Theory can be useful in entrepreneurship, as it is able to accommodate and integrate recent scholarly inquiries involving ADHD and other clinical and non-clinical constructs - based on a common neurological underpinning. For example, high BAS (particularly BAS-FS and BAS-RR) is associated with addiction and typically underlies high-risk and impulsive behavior, sensation seeking, and ADHD (e.g. Corr et al. 2017; Nigg 2000) - all of which have been recently linked to business venturing (e.g. Nicolaou et al., 2008; Spivack et al., 2014; Wiklund et al. 2017). High BAS 
sensitivity has also been associated with vulnerability to bipolar disorder as well as proneness to manic episodes (Alloy et al. 2006) - with a potential link between bipolar risk and entrepreneurship (Johnson \& Freeman 2016). Low BIS sensitivity is associated with psychopathy (Newman et al., 2005) while high BIS sensitivity is associated with anxiety and other internalizing disorders (Kimbrel et al. 2007; Nigg 2000) - any of which may influence venturing (e.g. Hmieleski \& Lerner 2016). Consequently, BIS/BAS and associated Reinforcement Sensitivity Theory can ground emerging research exploring the link between disorders such as ADHD, bipolar disorder, or depression, and entrepreneurship (e.g., Verheul et al. 2015; 2016; Thurik et al. 2016; Wiklund et al. 2016).

In summary, despite the relevance to entrepreneurship theory and phenomena, the relationship between BIS/BAS sensitivity and entrepreneurial action and performance is entirely untested. Adding to Geenen et al.'s (2016) study of entrepreneurial intentions, we now empirically examine the connection between BIS/BAS sensitivity and entrepreneurial outcomes.

\section{Method}

This section presents two independent studies, compiled from different samples and designs. The two studies share the same predictor variables of BIS/BAS sensitivity (operationalized with the BIS/BAS scales of Carver \& White 1994). The studies differ in their dependent variable, reflecting different aspects of the entrepreneurial process. Tradeoffs notwithstanding, this allows two distinct snapshots of the apparent link between BIS/BAS and entrepreneurship: as it relates to entrepreneurial action (operationalized as the extent of nascent entrepreneurial behavior if any), and to venture performance (operationalized as firm performance relative to competitors). 
In terms of control variables, there are a number of matters to consider. As deep psychophysiological systems, individual differences in BIS/BAS sensitivity underlie many higher-order individual differences (Carver \& White 1994; Carver 2005; Corr 2004; Gray 1994). Thus the primary question is not about the unique variance BIS/BAS explains in venturing beyond variables familiar to the entrepreneurship literature, but rather whether there is an observable association between BIS/BAS sensitivity and venturing. A lack of control variables for factors potentially connected to BIS/BAS does not threaten false-positive findings due to endogeneity, given the underling nature of BIS/BAS. It simply means that the specification of the particular ways (and higher-order constructs) through which BIS/BAS effects venturing will be challenging and require future research.

Additionally, there were a limited number of variables common across the two studies to serve as controls. Consequently, only the few common controls were used, in line with the objective of an initial inquiry (versus further testing of a reasonably well-established relationship or deriving generalizable parameter estimates or effect sizes). The two independent studies included controls for age, gender, and a relatively similar personality variable that was available across the two studies: conscientiousness (Goldberg 1992) and accomplishment-striving (Barrick et al., 2002) respectively. The inclusion of the latter served as an initial test as to if BIS/BAS explained unique variance beyond the potentially connected personality factor.

\subsection{Study 1: BIS/BAS and entrepreneurial action}

Study 1 tested the connection between BIS/BAS sensitivity and taking entrepreneurial action - specifically, the extent to which (if at all) an individual has engaged in nascent entrepreneurial behavior. Needing a group heterogeneous in having begun venturing, Study 1 
sampled 147 mid-level business Bachelor students. A total of 132 usable instruments were received. Sample characteristics are provided in Table 1.

Due to space limitations, the original BAS/BAS scale of 20 -items was reduced to 12 -items, with three items for each factor. The basis for distilling to three items per factor was that it would strike a balance between needing to thin on one hand, while on the other hand: providing the ability to calculate Cronbach alphas for all the trimmed scales, being sufficient to allow subsequent factor analysis, and capturing the vast majority of the original scale by trimming the weakest loading item(s). The specific 12 items were the highest ${ }^{2}$ loading items according to Carver and White (1994). Supporting the reasonableness of the thinned multi-item BIS/BAS variables, four clear factors emerged in factor analysis; all items loaded heavily on the corresponding four factors with negligible cross-loading. Additionally, Cronbach alpha estimates for each of the scales supported the three item variables. Details, including specific item factor loadings and scale alphas, are provided in the Appendix.

Dependent variable. Entrepreneurial action was operationalized with an index of 22 nascent entrepreneurial behaviors. Specifically, building on Farmer, Yao, and Kung-McIntyre's index (2011), respondents indicated 'yes' or 'no' to having engaged in various actions “toward starting or co-starting a venture." The activities of Farmer and colleagues (2011) were adapted from the PSED, such as "I have defined products or services for a business" and "I have studied and mapped out the financials for a business I was thinking to start." Additional entrepreneurial actions were included to cover other concrete behaviors such as "making business cards" and “developing a website.” Farmer and colleagues (2011) provide further discussion of the basis and validity of an entrepreneurial action index, with the validity of such indexes also supported by

\footnotetext{
${ }^{2}$ Note: there was an exception on one BAS-FS item. There, having to trim just one item, the decision was made to include the lower loading fourth item, rather than two more similar items.
} 
various other studies (e.g. Kautonen et al., 2015; Rauch \& Hulsink, 2015). The specific items comprising the index are included in the Appendix.

\subsection{Study 2: BIS/BAS and venture performance}

Study 2 tested the relationship between founding entrepreneurs' BIS/BAS sensitivity and venture performance. The sampling began by randomly selecting 400 operating business ventures (i.e., firms that employed at least one employee and were no older than eight years in age), from lists provided by a local chamber of commerce. Responses were received from 99 founders. Sample characteristics are provided in Table 2.

Dependent variable. Venture performance was operationalized based on prior research. Following Wiklund and Shepherd (2003), the entrepreneurs assessed their firm's performance over the past three years relative to their two main competitors on 10 facets of performance. These facets were: sales growth, revenue growth, growth in the number of employees, net profit margin, product/service innovation, process innovation, adoption of new technology, product/service quality, product/service variety, and customer satisfaction.

\section{Results}

Tables 1 and 2 display the descriptive statistics and intercorrelations. The tables indicate that BIS and BAS sensitivities are uncorrelated, whereas the BAS subscales of BAS-D, BASRR, and BAS-FS are moderately related. This is in line with prior research indicating that BIS and BAS are independent, and that overall BAS can be parsed into three dimensions (e.g. Carver \& White 1994; Geenen et al. 2016). 
Table 1: Study 1 Descriptive statistics and correlations

\begin{tabular}{lrrrrrrrrr} 
& Mean & $\begin{array}{r}\text { Std. } \\
\text { Dev. }\end{array}$ & 1 & 2 & 3 & 4 & 5 & 6 & 7 \\
\hline 1 Ent. Action (0-22) & 7.05 & 5.147 & & & & & & & \\
2 BIS & 2.62 & .657 & -.075 & & & & & & \\
3 BAS-D & 3.04 & .558 & $.246^{* *}$ & .082 & & & & & \\
4 BAS-RR & 3.50 & .445 & -.073 & .165 & $.330^{* *}$ & & & & \\
5 BAS-FS & 3.02 & .625 & .123 & -.057 & $.428^{* *}$ & $.383^{* *}$ & & & \\
6 Gender & 0.67 & .470 & $.280^{* * *}$ & $-.202^{*}$ & .038 & -.120 & -.078 & & \\
7 Age & 20.89 & 2.727 & $.320^{* * *}$ & -.100 & -.026 & -.063 & .024 & .050 & \\
8 Conscientiousness & 3.47 & .718 & -.138 & -.002 & -.053 & $.174^{*}$ & -.056 & $-.257^{* *}$ & .015 \\
\hline
\end{tabular}

$* \mathrm{p}<.05 ; * * \mathrm{p}<.01 ; 2$-tailed. Gender dummy coded ( $1=$ male, $0=$ female).

Table 2: Study 2 Descriptive statistics and correlations

\begin{tabular}{llllllllll} 
& Mean & $\begin{array}{c}\text { Std. } \\
\text { Dev. }\end{array}$ & \multicolumn{1}{c}{1} & 2 & 3 & 4 & 5 & 6 & 7 \\
\hline 1 Venture Performance & 3.63 & .51 & & & & & & \\
2 BIS & 2.45 & .53 & $-.36^{* *}$ & & & & & \\
3 BAS-D & 3.14 & .52 & .19 & -.02 & & & & \\
4 BAS-RR & 3.35 & .43 & .17 & .14 & $.51^{* *}$ & & & \\
5 B AS-FS & 2.92 & .64 & .08 & .15 & $.36^{* *}$ & $.36^{* *}$ & & \\
6 Gender & 0.71 & .46 & .12 & .18 & -.02 & .12 & -.01 & & \\
7 Age & 46.55 & 9.53 & -.08 & -.01 & $-.23^{*}$ & -.13 & -.03 & .01 & \\
8 Achievement Striving & 4.31 & .66 & .07 & .16 & .17 & .17 & .00 & $.20^{*}$ & .12 \\
\hline
\end{tabular}

$* \mathrm{p}<.05 ; * * \mathrm{p}<.01 ; 2$-tailed. Gender dummy coded (1=male, $0=$ female).

In terms of possible common method bias, single-factor tests were run. In Study 1, the largest factor that emerged explained $30 \%$ percent of the variance, considerably below the $50 \%$ threshold of concern. Examining the component matrices with and without rotation, in both, the variables loading to the largest factor were BAS-D, BAS-RR, and BAS-FS - consistent with an overall BAS that can be parsed into three sub-dimensions. In addition to the aforementioned loading to the first factor (all $\geq .7$ ), the dependent variable loaded primarily to its own separate factor (.68 without rotation, .66 with rotation) and showed negligible cross-loading to two other factors (<.28). In Study 2, the largest factor explained $18 \%$ of variance, even further below the $50 \%$ threshold of concern. While these results cannot definitively rule out potential commonmethod variance, they do suggest it did not present a problem. 
In terms of modeling, ordinary least squares regressions were first run. In order to test and report with robust standard errors, the regression models were subsequently rerun using the HCREG macro of Hayes and Cai (2007). The results were similar in both cases, with the latter reported in detail. Regression results for the two studies are presented in Tables 3 and 4.

Table 3: Study 1 Heteroscedasticity-Consistent Regression Results (Ordinary Least Squares with Robust Standard Errors)

\begin{tabular}{|c|c|c|c|c|}
\hline \multirow[b]{3}{*}{ Predictor Variables } & \multicolumn{4}{|c|}{ Predicting: Entrepreneurial Action (0-22) } \\
\hline & \multicolumn{2}{|c|}{ Model 1a } & \multicolumn{2}{|c|}{ Model 1b } \\
\hline & B Coeff. & S.E. & B Coeff. & S.E. \\
\hline Constant & -4.957 & 5.311 & $-9.516 \dagger$ & 5.648 \\
\hline Age & $0.583^{*}$ & 0.246 & $0.578^{*}$ & 0.228 \\
\hline Gender & $2.674 * *$ & 0.813 & $2.589 * *$ & 0.798 \\
\hline Conscientiousness & -0.573 & 0.531 & -0.296 & 0.597 \\
\hline BIS & & & 0.065 & 0.736 \\
\hline BAS-D & & & $2.334 *$ & 0.947 \\
\hline BAS-RR & & & -1.532 & 1.383 \\
\hline BAS-FS & & & 0.616 & 0.736 \\
\hline \multicolumn{5}{|l|}{ Total Model } \\
\hline $\mathrm{R}^{2}$ & \multirow{2}{*}{\multicolumn{2}{|c|}{$0.179 * * *$}} & \multicolumn{2}{|c|}{$0.251 * * *$} \\
\hline$\Delta \mathrm{R}^{2}$ & & & \multicolumn{2}{|c|}{$0.072 *$} \\
\hline $\mathrm{N}$ & \multicolumn{2}{|c|}{132} & \multicolumn{2}{|c|}{132} \\
\hline
\end{tabular}


Table 4: Study 2 Heteroscedasticity-Consistent Regression Results (Ordinary Least Squares with Robust Standard Errors)

\begin{tabular}{|c|c|c|c|c|}
\hline \multirow[b]{3}{*}{ Predictor Variables } & \multicolumn{4}{|c|}{ Predicting: Venture Performance } \\
\hline & \multicolumn{2}{|c|}{ Model 1a } & \multicolumn{2}{|c|}{ Model 1b } \\
\hline & B Coeff. & S.E. & B Coeff. & S.E. \\
\hline Constant & $3.615^{* * *}$ & 0.533 & $3.674 * * *$ & 0.612 \\
\hline Age & -0.004 & 0.007 & -0.003 & 0.007 \\
\hline Gender & 0.138 & 0.171 & 0.101 & 0.150 \\
\hline Ach. Striving & 0.007 & 0.091 & 0.013 & 0.095 \\
\hline BIS & & & $-0.442 * *$ & 0.135 \\
\hline BAS-D & & & 0.052 & 0.136 \\
\hline BAS-RR & & & $0.292 \dagger$ & 0.168 \\
\hline BAS-FS & & & -0.055 & 0.095 \\
\hline \multicolumn{5}{|l|}{ Total Model } \\
\hline $\mathrm{R}^{2}$ & \multirow{2}{*}{\multicolumn{2}{|c|}{0.020}} & \multicolumn{2}{|c|}{$0.229 \dagger$} \\
\hline$\Delta \mathrm{R}^{2}$ & & & \multicolumn{2}{|c|}{$0.209 * *$} \\
\hline $\mathrm{N}$ & \multicolumn{2}{|l|}{74} & \multicolumn{2}{|c|}{74} \\
\hline
\end{tabular}

In examining the results, we begin by reminding of the overall objective - initial inquiry, rather than extending something already well-established in entrepreneurship. The results should be interpreted as offering a basis for follow-on inquiry as opposed to parameter estimates expected to generalize or a well-powered comprehensive test of a given relationship.

The results show some significant links between BIS/BAS sensitivities and entrepreneurial action and performance. Indeed, the predictive role of BIS and of the three subdimensions of BAS differed according to the entrepreneurial variable of concern. BAS-Drive was positively related to entrepreneurial action $(\mathrm{B}=2.334, p=.015$; Study 1$)$; it however was not a significant predictor of venture performance ( $\mathrm{B}=0.052, p>.1$; Study 2$)$. In other words, greater BAS sensitivity corresponding to the Drive sub-dimension was associated with nascent entrepreneurial behavior; it however did not differentiate reported performance among the fulltime entrepreneurs sampled. Conversely, BIS sensitivity was negatively related to venture 
performance $(\mathrm{B}=-0.442, p<.01$; Study 2$)$, but showed no significant connection to entrepreneurial action ( $\mathrm{B}=0.065, p>.1$; Study 1$)$. There was also one marginally significant link observed, that of a positive connection between BAS-RR and venture performance ( $\mathrm{B}=0.292, p=.087$; Study 2$)$. These results are discussed in the next section.

Overall, the findings support the thesis that BIS/BAS Reinforcement Sensitivity Theory is germane to entrepreneurship. Looking across the two independent studies, the significant variance uniquely explained by BIS/BAS ranged from $7 \%\left(\Delta \mathrm{R}^{2,}\right.$ Study 1$)$ to $21 \%\left(\Delta \mathrm{R}^{2,}\right.$ Study 2$)$. Taken together, the results suggest that the role of BIS/BAS in differentiating who will act and to what ends, may increase as the entrepreneurial process unfolds.

\section{Discussion and conclusions}

Acknowledging top-down higher-order individual predictors of entrepreneurship, this paper offers a complementary more bottom-up perspective - by considering the linkages between underlying behavioral inhibition and behavioral activation system sensitivity and entrepreneurship. The results of our two independent studies support the notion of BIS/BAS sensitivity being a root that shapes entrepreneurial action and performance.

For example, we found that BIS was negatively related to venture performance. This suggests that being quite sensitive to threats and punishment may, on-average, inhibit venture performance. BIS sensitivity was however not negatively related to entrepreneurial action (Study 1), or to entrepreneurial intentions in Geenen et al.'s (2016) study. To the extent entrepreneurial action is "behavior in response to a judgmental decision under uncertainty about a possible opportunity for profit" (McMullen \& Shepherd 2006: 134), this is intriguing. On one hand, a negative link between BIS and entrepreneurial action might be expected due to the novelty/uncertainty present. However, a possibly offsetting concurrent link might be at hand, 
masking a general overall nascent-stage effect. BIS may be negatively linked to some entrepreneurial activities yet positively linked to others that attempt to understand and manage down-side threats such as business planning and prototype testing. At the nascent stage, individuals need to undertake numerous and different entrepreneurial activities to make their ventures more concrete to themselves and others (Shepherd \& Patzelt 2017). Once the business is established and running, the entrepreneur needs to continue engaging in both opportunity exploitation as well as new opportunity development to sustain firm performance. Here, higher BIS sensitivity may obstruct the latter, hampering willingness to take innovation risks, leading to diminished venture performance.

Similarly, the sub-dimensions of BAS varied in their relations across the two studies. For example: BAS-Drive, while not linked to entrepreneurial intentions in individuals without prior entrepreneurial experience (Geenen et al., 2016), appeared instrumental for initiating early-stage entrepreneurial action (Study 1); a strong drive is needed to push forward, undertake many gestation activities, and make things happen. Given the hard, and at times mundane reality of business venturing, this makes sense. It is also generally fitting with Geenen et al.'s (2016) other finding that among individuals with prior venturing experience, BAS-D was positively linked to entrepreneurial intentions. While it reasons that such drive could serve venture performance, it did not uniquely predict performance among business founders (Study 2).

It is also interesting to consider BAS-FS as it relates to our findings and those of Geenen and colleagues (2016). While the novelty and uncertainty of entrepreneurship is likely enticing to the unfamiliar fun-seeker (e.g. Geenen and colleagues' finding of a positive BAS-FS —intentions link in the unexperienced), BAS-FS was not related to entrepreneurial intentions in those with prior experience (Geenen et al., 2016) or with actually taking entrepreneurial action (Study 1). 
And yet, within at least some entrepreneurs, novelty seeking appears to be an important driver of venturing (e.g. Branson, 2002; Wiklund et al., 2016; Lerner et al., 2018a). Thus, while it might not have an observable effect on predicting nascent organizing or performance on average, the consideration thereof seems relevant in subsequent research and theory development.

Greater sensitivity to rewards (BAS-RR) was positively though marginally $(\mathrm{p}<.1)$ associated with venture performance, but not with nascent entrepreneurial action. Geenen and colleagues (2016) found it negatively associated with entrepreneurial intentions. This could be interpreted as follows: reward responsiveness is positively connected to performance as it motivates founders to keep exploiting the (rewarding) opportunity, including well-after the original vision has been realized and once the novelty fades; however at the stage of nascent entrepreneurial behavior, entrepreneurial rewards are sufficiently uncertain that higher reward responsiveness is not associated with a greater proclivity for taking action. This is consistent with the suggestion of Geenen and colleagues (2016) that the negative link they observed may relate to that when action itself it not intrinsically reinforcing, things other than entrepreneurship may offer greater rewards.

In terms of limitations, the two empirical studies presented have many. Fundamentally, they provide two distinct snapshots of linkages between BIS/BAS and, respectively, nascent entrepreneurial behavior and venture performance. Given the relatively simple study designs, the modest sample sizes, and the dependent variable operationalizations - the results suggest various future research opportunities. For example, studies using more complex designs and alternative performance measures will be important to consider alternative explanations and reveal more fine-grained insights. Entrepreneurship research can also elaborate, and test with larger samples, BIS/BAS as interacting (sub)systems (Corr, 2002) - examining for example the effects of 
relative BIS/BAS ratios on venturing (e.g. metaphorically, akin to a vehicle's engine to braking system ratio). In terms of the BIS/BAS measure, while not a direct physiological measure, the self-report scales of BIS/BAS sensitivity have been extensively validated (including with direct physiological evidence) and widely used in the psychology literature (e.g., Bijttebier et al., 2009; Carver \& White 1994; Hogan \& Holland 2003). Thus future empirical research and theory development by entrepreneurship scholars should be tractable and fruitful.

Overall, this research makes a number of contributions. It extends a novel perspective for the literature on motivation in entrepreneurship. Specifically, Reinforcement Sensitivity Theory allows for capturing deep underlying motives, stable differences in system sensitivities, and the associated amplitude of individual responses. Additionally, BIS/BAS RST does not require assumptions of considerable reasoning to underlie entrepreneurial action, responding to recent calls (Lerner, Hunt \& Dimov, 2018; Wiklund, Yu \& Patzelt, 2017). As such, it also serves related research involving biological drivers as well as a-rational clinical conditions associated with entrepreneurship (e.g., Koellinger et al. 2010; Thurik et al. 2016; van der Loos et al. 2010; Verheul et al. 2015; 2016). Taking BIS/BAS into consideration with cognitive motivational theories already present the entrepreneurship literature, can enrich and more fully complete our understanding of the role of entrepreneurial motives.

This research also has implications for process theories in the domain of entrepreneurship. What makes entrepreneurship particularly challenging is that both independent and dependent variables change as the venturing process unfolds (Baron \& Markman 2005; McMullen \& Dimov 2013). Basic individual difference sensitivities are a prime candidate of an independent variable whose affect is likely to change according to the environmental stimuli at hand, not mention effect which of innumerable stimuli are even attended to. Our work extends recent 
research (e.g., Geenen et al. 2016; Lerner 2016; Lerner et al., 2018a/b), showing that behavioral (dis)inhibition appears differentially relevant to various components and points of the entrepreneurial process. As our findings imply, it is likely that the nature and strength of cues of threat and reward vary at different stages of the entrepreneurial process. Thus individual differences in BIS/BAS sensitivity can explain heterogeneous behavior and outcomes at varying stages of the entrepreneurial process - including reactions to outcomes that, in in turn, affect subsequent outcomes. Consequently, process and motivational approaches in the domain of entrepreneurship need to be combined to comprehensively address the dynamics of entrepreneurship.

Finally, akin to the work of Bijttebier and colleagues (2009) focusing on clinical psychology, our work suggests that BIS/BAS offers a useful lens for organizing and analyzing various factors related to entrepreneurship. RST offers a conceptually, theoretically, and biologically grounded 'mortar' that, with further research and development, can be used to connect research and theory on impulsivity, clinical conditions, personality, and motivation in entrepreneurship. As RST and BIS/BAS underlie the aforementioned, they offer a basis for a potentially unifying theory and empirical lens. While future research is needed, our work motivates and helps open the opportunity for further inquiry. 


\section{References}

Alloy, L., Abramson, L., Walshaw, P., Cogswell, A., Smith, J., Neeren, A., et al. (2006). Behavioral approach system (BAS) sensitivity and bipolar spectrum disorders: A retrospective and concurrent behavioral high-risk design. Motivation and Emotion, 30, 143-155.

Baron, R. A. (2007). Behavioral and cognitive factors in entrepreneurship: Entrepreneurs as the active element in new venture creation. Strategic Entrepreneurship Journal, 1(1-2), 167-182.

Baron, R. A. (2008). The role of affect in the entrepreneurial process. Academy of Management Review, 33(2), 328-340.

Baron, R. A., \& Markman, G. D. (2005). Toward a process view of entrepreneurship: The changing impact of individual level variables across phases of new venture development. Current Topics in Management, 9, 45-64.

Barrick, M. R., Stewart, G. L., \& Piotrowski, M. (2002). Personality and job performance: test of the mediating effects of motivation among sales representatives. Journal of Applied Psychology, 87(1), 4351.

Baum, J. R., \& Locke, E. A. (2004). The relationship of entrepreneurial traits, skill, and motivation to subsequent venture growth. Journal of Applied Psychology, 89(4), 587-598.

Bijttebier, P., Beck, I., Claes, L., \& Vandereycken, W. (2009). Gray's Reinforcement Sensitivity Theory as a framework for research on personality-psychopathology associations. Clinical Psychology Review, 29(5), 421-430.

Branson, R. (2002) Losing my Virginity: The Autobiography. Virgin Books, London

Carver C. \& White T. (1994). Behavioral inhibition, behavioral activation, and affective responses to impending reward and punishment: The BIS/BAS scales. Journal of Personality and Social Psychology, 67(2), 319-333.

Corr, P.J., (2002). JA Gray's reinforcement sensitivity theory: Tests of the joint subsystems hypothesis of anxiety and impulsivity. Personality and individual differences, 33(4), 511-532.

Corr, P.J. (2004). Reinforcement Sensitivity Theory and Personality, Neuroscience and Biobehavioral Reviews, 28: 317-332.

Cloninger, C. R. (1987). A systematic method for clinical description and classification of personality variants: A proposal. Archives of General Psychiatry, 44(6), 573-588.

De Clercq, D., Menzies, T. V., Diochon, M., \& Gasse, Y. (2009). Explaining nascent entrepreneurs' goal commitment: An exploratory study. Journal of Small Business \& Entrepreneurship, 22(2), 123-139.

Diefendorff, J. M., \& Mehta, K. (2007). The relations of motivational traits with workplace deviance. Journal of Applied Psychology, 92, 967-977.

Farmer, S., Yao, X., \& Kung-McIntyre, K. (2011). The behavioral impact of entrepreneur identity aspiration and prior entrepreneurial experience. Entrepreneurship Theory \& Practice, 35(2), 245-273.

Frese, M., Kring, W., Soose, A., \& Zempel, J. (1996). Personal initiative at work: Differences between East and West Germany. Academy of Management Journal, 39(1), 37-63.

Geenen, N., Urbig, D., Muehlfeld, K., van Witteloostuijn, A., \& Gargalianou, V. (2016). BIS and BAS: Biobehaviorally rooted drivers of entrepreneurial intent. Personality and Individual Differences, 95, 204-213.

Goldberg, L. R. (1992). The development of markers for the Big-Five factor structure. Psychological Assessment, 4(1), 26-42.

Gray, J. A. (1970). The psychophysiological basis of introversion-extraversion. Behaviour Research and Therapy, 8(3), 249-266. 
Gray, J. A. (1982). The neuropsychology of anxiety: An enquiry into the functions of the septohippocampal system. Oxford: Oxford University Press.

Gray, J. A. (1991). Neural systems of motivation, emotion and affect. In J. Madden (Ed.), Neurobiology of learning, emotion and affect (pp. 273-306). New York: Raven Press.

Gray, J. A. (1994). Personality dimensions and emotion systems. In P. Ekman, \& R. J. Davidson (Eds.), The nature of emotion (pp. 329-331). New York: Oxford University Press.

Gray, J. A., \& McNaughton, N. (2000). The neuropsychology of anxiety: An enquiry into the functions of the septo-hippocampal system. Oxford: Oxford University Press.

Hatak, I., \& Snellman, K. (2017). The influence of anticipated regret on business start-up behavior. International Small Business Journal, 35(3), 349-360.

Hayes, A. F., \& Cai, L. (2007). Using heteroscedasticity-consistent standard error estimators in OLS regression: An introduction and software implementation. Behavior Research Methods, 39, 709-722.

Hmieleski, K.M. \& Lerner, D. (2016). The Dark Triad and Nascent Entrepreneurship: An Examination of Unproductive versus Productive Entrepreneurial Motives. Journal of Small Business Management, 54(S1), 7-32. doi: 10.1111/jsbm.12296.

Hogan, J., \& Holland, B. (2003). Using theory to evaluate personality and job performance relations: A socioanalytic perspective. Journal of Applied Psychology, 88, 100-112.

Hollenbeck, J. R., Williams, C. R., \& Klein, H. J. (1989). An empirical examination of the antecedents of commitment to difficult goals. Journal of Applied Psychology, 74(1), 18-23.

Johnson, S. L. \& Freeman, M. (2016). Bipolar disorder and entrepreneurship: Personality as a potential mechanism driving entrepreneurial intent and success. In "Entrepreneurship and Mental Health Workshop." Conference at Syracuse University, Syracuse, NY.

Kanfer, R. (1992). Work motivation: New directions in theory and research. In C. L. Cooper, \& I. T. Robertson (Eds.), Review of Industrial and Organizational Psychology. London: John Wiley \& Sons.

Kautonen, T., Gelderen, M., \& Fink, M. (2015). Robustness of the theory of planned behavior in predicting entrepreneurial intentions and actions. Entrepreneurship Theory and Practice, 39(3), 655674.

Kimbrel, N. A., Nelson-Gray, R. O., \& Mitchell, J. T. (2012). BIS, BAS, and bias: The role of personality and cognitive bias in social anxiety. Personality and Individual Differences, 52(3), 395-400.

Koellinger, P. D., van der Loos, M. J., Groenen, P. J., Thurik, A. R., et al. (2010). Genome-wide association studies in economics and entrepreneurship research: promises and limitations. Small Business Economics, 35(1), 1-18.

Lerner, D., Hunt, R., \& Dimov, D. (2018a). Action! Moving Beyond the Intendedly-Rational Logics of Entrepreneurship. Journal of Business Venturing, 33(1), 52-69. doi: 10.1016/j.jbusvent.2017.10.002

Lerner, D., Hunt, R., \& Verheul, I. (2018b) Dueling Banjos: Harmony and Discord between ADHD and Entrepreneurship. Academy of Management Perspectives. doi:10.5465/amp.2016.0178.

Lerner, D., Verheul, I., \& Thurik, R. (2018c). Entrepreneurship \& Attention Deficit/Hyperactivity Disorder: A Large-Scale Study involving the Clinical Condition of ADHD. conditionally accepted paper at SBEJ.

Lerner, D. (2016). Behavioral Disinhibition \& Nascent Venturing: Relevance and Initial Effects on Potential Resource Providers. Journal of Business Venturing, 31(2), 234-252.

Lerner, D., Fitza, M. (2012) Disinhibition \& Entrepreneurial Behavior: A New and Integrative Predictor of Entrepreneurial Action. Front. Entrep. Res., 32(6), 22.

Lerner, D. (2010) Disinhibition, Inhibitory Control, \& Entrepreneurship. Front. Entrep. Res., 30(6), 12.

Locke, E. A., \& Baum, J. R. (2007). Entrepreneurial motivation. In J. R. Baum, M. Frese, \& R. A. Baron (Eds.), The psychology of entrepreneurship. Mahwah, NJ: Lawrence Erlbaum Associates Publishers. 
McFarland, B. R., Shankman, S. A., Tenke, C. E., Bruder, G. E., \& Klein, D. N. (2006). Behavioral activation system deficits predict the six-month course of depression. Journal of Affective Disorders, 91, 229-234.

McMullen, J. S., \& Dimov, D. (2013). Time and the entrepreneurial journey: The problems and promise of studying entrepreneurship as a process. Journal of Management Studies, 50(8), 1481-1512.

McMullen, J. S., \& Shepherd, D. A. (2006). Entrepreneurial action and the role of uncertainty in the theory of the entrepreneur. Academy of Management Review, 31(1), 132-152.

Newman, J. P., MacCoon, D. G., Vaughn, L. J., \& Sadeh, N. (2005). Validating a distinction between primary and secondary psychopathy with measures of Gray's BIS and BAS constructs. Journal of Abnormal Psychology, 114, 319-323.

Spivack, A., McKelvie, A., Haynie, J. (2014). Habitual entrepreneurs: possible cases of entrepreneurship addiction. Journal of Business Venturing 29 (5), 651-667

Nicolaou, N., S. Shane, L. Cherkas, T. Spector (2008). The influence of sensation seeking in the heritability of entrepreneurship. Strategic Entrepreneurship Journal, 2, 7-21

Nigg, J. T. (2000). On inhibition/disinhibition in developmental psychopathology: Views from cognitive and personality psychology and a working inhibition taxonomy. Psychological Bulletin, 126(2), 220246.

Phelps, E.A. (2006) Emotion and cognition: Insights from studies of the human amygdala. Annual Review of Psychology, 57: 27-53.

Phelps E.A., O'Connor KJ, Gatenby JC, Gore JC, Grillon C, Davis M. (2001) Activation of the left amygdala to a cognitive representation of fear. Nature Neuroscience, 4: 437-441.

Przepiorka, A. (2016). What makes successful entrepreneurs different in temporal and goal-commitment dimensions?. Time \& Society, 25(1), 40-60.

Shane, S. A. (2003). A general theory of entrepreneurship: The individual-opportunity nexus. Cheltenham: Edward Elgar Publishing.

Shepherd, D. A., \& Patzelt, H. (2017). Trailblazing in Entrepreneurship: Creating New Paths for Understanding the Field. Cham: Springer.

Thurik, R., Khedhaouria, A., Torrès, O., \& Verheul, I. (2016). ADHD symptoms and entrepreneurial orientation of small firm owners. Applied Psychology, 65(3), 568-586.

van der Loos, M. J. H. M., Koellinger, P. D., Groenen, P. J. F., \& Thurik, A. R. (2010). Genome-wide association studies and the genetics of entrepreneurship. European Journal of Epidemiology, 25, 1-3.

Verheul, I., Block, J., Burmeister-Lamp, K., Thurik, R., Tiemeier, H., \& Turturea, R. (2015). ADHD-like behavior and entrepreneurial intentions. Small Business Economics, 45(1), 85-101.

Verheul, I., Rietdijk, W., Block, J., Franken, I., Larsson, H., \& Thurik, R. (2016). The association between attention-deficit/hyperactivity (ADHD) symptoms and self-employment. European Journal of Epidemiology, 31(8), 793-801.

Wiklund, J., Patzelt, H., \& Dimov, D. (2016). Entrepreneurship and psychological disorders: How ADHD can be productively harnessed. Journal of Business Venturing Insights, 6, 14-20.

Wiklund, J., \& Shepherd, D. (2003). Knowledge-based resources, entrepreneurial orientation, and the performance of small and medium-sized businesses. Strategic Management Journal, 24(13), 13071314.

Wiklund, J., Yu, W., \& Patzelt, H. (2017). Impulsivity and Entrepreneurial Action. Academy of Management Perspectives, DOI: 10.5465/amp.2016.0177

Wiklund, J., Yu, W., Tucker, R., \& Marino, L. (2017). ADHD, Impulsivity, and Entrepreneurship. Journal of Business Venturing, 32 (6), 627-656. 


\section{APPENDIX}

\section{Multivariate factor loadings \& Cronbach alphas of Study 1 trimmed BAS/BAS variables:}

Multivariate Factor Analysis (Pattern Matrix)

\begin{tabular}{|c|c|c|c|c|}
\hline & \multicolumn{4}{|c|}{ Factor } \\
\hline & 1 (BAS-D) & 2 (BIS) & 3 (BAS-RR) & 4 (BAS-FS) \\
\hline BAS-D -I go out of my way to get things I want & .840 & & & \\
\hline BAS-D -When I want something I usually go all-out to get it & .806 & & & \\
\hline BAS-D -If I see a chance to get something I want I move on it right away & .784 & & & \\
\hline $\begin{array}{l}\text { BIS -If I think something unpleasant is going to happen I usually get pretty } \\
\text { "worked up" }\end{array}$ & & .895 & & \\
\hline BIS -I worry about making mistakes & & .799 & & \\
\hline BIS -Criticism or scolding hurts me quite a bit & & .738 & & \\
\hline BAS-RR -When good things happen to me, it affects me strongly & & & .890 & \\
\hline BAS-RR -When I get something I want, I feel excited and energized & & & .795 & \\
\hline BAS-RR -When I'm doing well at something I love to keep at it & & & .600 & \\
\hline BAS-FS -I often act on the spur of the moment & & & & .878 \\
\hline BAS-FS -I crave excitement and new sensations & & & & .773 \\
\hline BAS-FS -I'm always willing to try something new if I think it will be fun & & & & .747 \\
\hline
\end{tabular}

Extraction Method: Principal Component Analysis; Initial Eigenvalues >1; cumulative variance explained: 67.23\%. Rotation: Promax with Kaiser Normalization. Rotation converged in 5 iterations. Loadings below .4 not shown.

Cronbach alphas $(\alpha)$ :

BAS-D $\alpha=0.80$; BAS-FS $\alpha=0.74$; BAS-RR $\alpha=0.7$; BIS $\alpha=0.75$. 